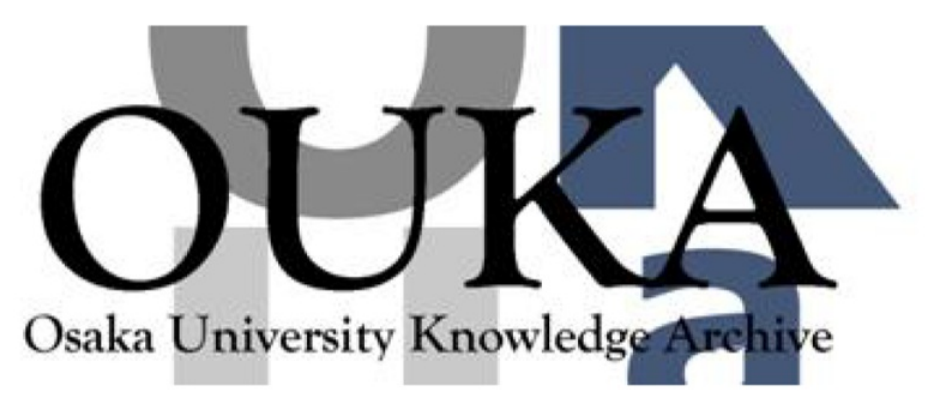

\begin{tabular}{|c|l|}
\hline Title & $\begin{array}{l}\text { Modification of rust layer on carbon steel with } \\
\text { reactive actions of metallic cations for } \\
\text { improved corrosion protectiveness }\end{array}$ \\
\hline Author(s) & $\begin{array}{l}\text { Kim, Kyung Tae; Tsuchiya, Hiroaki; Hanaki, } \\
\text { Koushu et al. }\end{array}$ \\
\hline Citation & Corrosion. 76(4) p. 335-p. 343 \\
\hline Issue Date & $2020-02-03$ \\
\hline oaire:version AM \\
\hline URL & https://hdl. handle. net/11094/82369 \\
\hline rights & \\
\hline Note & \\
\hline
\end{tabular}

Osaka University Knowledge Archive : OUKA

https://ir. Library. osaka-u. ac. jp/

Osaka University 


\section{Modification of Rust Layer on Carbon Steel with Reactive Actions of Metallic Cations for Improved Corrosion Protectiveness}

\author{
Kyung-Tae Kim, * Hiroaki Tsuchiya, ${ }^{*}$ Koushu \\ Hanaki, ${ }^{* * *}$ Masato Yamashita, ${ }^{* * * *}$ and Shinji \\ Fujimoto. ${ }^{\neq *} *$
}

* Division of Materials and Manufacturing Science, Graduate School of Engineering, Osaka University.

** Kyoto Materials Co. Ltd.

\begin{abstract}
ARTICLE INFO
Article history:

Received Day Month Year Accepted Day Month Year Available Day Month Year

Keywords:

atmospheric corrosion rusted carbon steel wet/dry cyclic corrosion cation

* Division of Materials and Manufacturing Science, Graduate School of Engineering, Osaka University, 2-1 Yamada-oka, Suita, Osaka 565-0871 Japan.

** Kyoto Materials Co. Ltd., Kyodai-Katsura Venture Plaza, South-2102, 1-39 Goryo-Ohara, Nishikyo-ku, Kyoto 615-8245 Japan.

${ }^{\ddagger}$ Corresponding author: Email: (E-mail: fujimoto@mat.eng.osaka-u.ac.jp).
\end{abstract}

\footnotetext{
ABSTRACT

In the present work, we examined the modification of a rust layer on a carbon steel surface during a cyclic corrosion test. The rust layer grown in a coastal region of Japan was used as a model rust layer. The $X$-ray diffraction analysis of the model rust layer revealed that the layer consisted of $\alpha-\mathrm{FeOOH}, \beta-\mathrm{FeOOH}, \gamma-\mathrm{FeOOH}$, and $\mathrm{Fe}_{3} \mathrm{O}_{4}$. During the cyclic corrosion test, an additional immersion of the surface in solutions containing metal cations such as $\mathrm{Mg}^{2+}, \mathrm{Al}^{3+}, \mathrm{Cu}^{2+}$, or $\mathrm{Ni}^{2+}$ was performed. The additional immersion in the cation-containing solutions modified the model rust layer, that is, the fraction of stable $\alpha-\mathrm{FeOOH}$ increased in the rust layer. Furthermore, the modification of the model rust layer could suppress the corrosion of steel. The decreased corrosion rate was attributed to the suppressed cathodic reduction of the rust layers due to the presence of the stable $\alpha$-FeOOH in the rust layers.
}

\section{INTRODUCTION}

Steel has been employed as structural material due to its abundance as well as superior properties in strength, toughness and workability. ${ }^{1-}$ 3) In Japan, many infrastructures have been built using steel in the high economic growth period of the 1960s. ${ }^{4}$ ) The constructions made of steel cannot avoid degradation due to atmospheric corrosion when they are used in atmospheric environments where water, oxygen and other corrosive species are present. According to the atmospheric corrosion process proposed by Evans et al., ${ }^{5)}$ during the wet period, the anodic and the cathodic reactions expressed in the equations (1) and (2), respectively, are balanced under rust layer formed on steel.

$\mathrm{Fe} \rightarrow \mathrm{Fe}^{2+}+2 \mathrm{e}^{-}$

$8 \mathrm{FeOOH}+\mathrm{Fe}^{2+}+2 \mathrm{e}^{-} \rightarrow 3 \mathrm{Fe}_{3} \mathrm{O}_{4}+4 \mathrm{H}_{2} \mathrm{O}$

In the drying period, the supply of oxygen through the rust layer occurs effectively, and the oxygen re-oxidizes the formed $\mathrm{Fe}_{3} \mathrm{O}_{4}$, according to the following equation (3).

$$
3 \mathrm{Fe}_{3} \mathrm{O}_{4}+3 / 4 \mathrm{O}_{2}+9 / 2 \mathrm{H}_{2} \mathrm{O} \rightarrow 9 \mathrm{FeOOH}
$$

Based on the model, one can deduce that the corrosion proceeds during the repeated wet-dry cycle once steel corrodes to form a rust layer in the atmospheric environment. If rusted steel constructions continue to be used while they are aged without being repaired, serious accidents would occur. 6,7$)$

It is well-known that the rust layers formed on steel in atmospheric environments consist of $\alpha-\mathrm{FeOOH}, \beta-\mathrm{FeOOH}, \gamma$ - $\mathrm{FeOOH}, \mathrm{Fe}_{3} \mathrm{O}_{4}$ and poorly crystallized iron oxides. ${ }^{8-10)}$ Further, the fraction of the phases in the rust layers is strongly affected by the environment in which the rust layers grow. ${ }^{11)}$ In addition, the electrochemical properties of the rust layers are reported to be different, for example, $\alpha-\mathrm{FeOOH}$ is electrochemically stable compared to the other types of oxyhydroxides. ${ }^{12,13)}$ Therefore, if the fraction of $\alpha-\mathrm{FeOOH}$ increases in the rust layer on steel, the cathodic reaction expressed in the equation (2) can be hindered, leading to a suppressed atmospheric corrosion. Weathering steel has been reported to form a protective rust layer on its surface. Therefore, it exhibits superior atmospheric corrosion resistance. Extensive studies have revealed that alloying elements such as $\mathrm{Cu}$ and $\mathrm{Cr}$ in weathering steels are enriched in rust layers and contribute to the excellent protectiveness of the rust layers. ${ }^{14-17)}$ This finding implies that the introduction of metallic cations in rust layers modifies the structure and composition of the rust layers as well as their protectiveness, thereby contributing to an improved atmospheric corrosion resistance. If the introduction of metallic cations in rust layers is realized by a post-treatment, the approach will be useful for the repair of rusted steel constructions.

In the present work, we examined the feasibility of our idea, that is, the introduction of metallic cations in a rust layer grown on carbon steel to modify the structure and composition of the rust layer and its resulting electrochemical properties. For this purpose, we performed the immersion of rusted steel in cation-containing solutions during a wet/dry cyclic corrosion test. 


\section{EXPERIMENTAL PROCEDURE}

The material used was a carbon steel (SS400-JIS G3101) sheet with a thickness of $3 \mathrm{~mm}$. The chemical composition of the steel was as follows (mass\%) ; C: 0.05, Si: 0.03, Mn: 0.33, P: 0.016, S: 0.01, Fe: bal. The carbon steel sheet was exposed to a coastal environment in Obama City, Fukui Prefecture in Japan for three months, during which, a rust layer grew on the steel surface. The city is situated at lat. $35^{\circ} 53^{\prime}$ $\mathrm{N}$. and long. $135^{\circ} 75^{\prime} \mathrm{E}$. Average airborne salt at the site is estimated as $1.0 \mathrm{mg} \mathrm{NaCl} / \mathrm{dm}^{2} /$ day. After the exposure, the rusted carbon steel was cut into as-rusted specimens to be used for the cyclic corrosion test, characterization and electrochemical measurements described below. The specimens were rinsed in methanol and then dried in air prior to further experiments.

The rusted specimens were subjected to a laboratory cyclic corrosion test in accordance with the SAE J2234 ${ }^{18}$ ) that consists of three stages: the humid stage, immersion stage, and dry stage. These stages simulate a severe atmospheric corrosion environment where chloride is present. Therefore, the SAE J2234 test has often been used to evaluate the atmospheric corrosion resistance of steel in severe conditions. ${ }^{19,}{ }^{20}$ ) In the humid stage, the rusted specimens were held for $6 \mathrm{~h}$ in an environment with a temperature of $50^{\circ} \mathrm{C}$ and a relative humidity (R. H.) of $100 \%$. In the subsequent immersion stage, the specimens were placed in a mixed solution of 0.5 mass $\% \mathrm{NaCl}, 0.1$ mass $\% \mathrm{CaCl}_{2}$ and 0.075 mass $\% \mathrm{NaHCO}_{3}$ for $15 \mathrm{~min}$. Thereafter, they were held for $17 \mathrm{~h} 45 \mathrm{~min}$ at $60^{\circ} \mathrm{C}$ and $50 \%$ R. H. (dry stage). These three processes were repeated for up to 30 cycles in the present study. It should be noted that from the 2 nd cycle, the specimens were additionally immersed in a solution of $1 \mathrm{M} \mathrm{MgSO}_{4}, \mathrm{Al}_{2}\left(\mathrm{SO}_{4}\right)_{3}, \mathrm{CuSO}_{4}$, or $\mathrm{NiSO}_{4}$ for $5 \mathrm{~s}$ prior to the humid stage at each cycle. These specimens are hereafter referred to as $\mathrm{Mg}^{2+}, \mathrm{Al}^{3+}, \mathrm{Cu}^{2+}$, or $\mathrm{Ni}^{2+}$ specimens, respectively. Some rusted specimens were not subjected to the additional immersion, but to only the cyclic corrosion test (referred to as the "reference specimens").

To evaluate the electrochemical properties of the as-rusted specimen, the reference specimens as well as specimens subjected to the additional immersion, potentiodynamic polarization measurements were accomplished in a conventional three-electrode configuration cell with a $\mathrm{Ag} / \mathrm{AgCl} / \mathrm{KCl}$ (sat.) reference electrode and a platinum counter electrode. The solution used for the electrochemical measurements was the same as the one used in the immersion stage of the cyclic corrosion test, as explained above. The potentiodynamic polarization was conducted at a scan rate of $0.5 \mathrm{mV} \mathrm{s}^{-1}$ without the deaeration of the solution. Furthermore, in the present work, to examine the reduction reaction on the rust layers of all specimens, the cathodic polarization curves were also measured in the mixed solution of chlorides and bicarbonate. For the cathodic polarization, the potential was swept to $500 \mathrm{mV}$ lower than the open circuit potential of each specimen with a scan rate of $0.5 \mathrm{mV} \mathrm{s}^{-1}$. These morphological, structural and electrochemical characterizations were carried out using a single specimen for each cycle of the cyclic corrosion test to avoid possible individual differences of specimens after the exposure to the coastal environments for three months.

The morphology of the specimen surfaces was examined by scanning electron microscopy (SEM, JEOL JSM-5600) with an accelerating voltage of $25 \mathrm{kV}$, whereas the phase of the rust layers on the specimens was identified with $\mathrm{X}$-ray diffraction using a Cu target operated at $45 \mathrm{kV}$ and $40 \mathrm{~mA}$ in a Phillips X'pert X-ray diffractometer.

\section{RESULTS}

\subsection{Morphology and composition of rust layer}

Figure 1(a) shows the SEM image of the surface of the as-rusted specimen which was exposed to a coastal environment in Obama City,
Fukui Prefecture for three months. It is clear that the specimen shows a plate-like morphology, similar to that found in the literature. ${ }^{21,22)}$ This plate-like rust layer is supposedly not protective as water and corrosive ions can penetrate through the hollows in the rust to the underlying steel substrate. ${ }^{23}{ }^{24)}$ The as-rusted specimen was examined by X-ray diffraction (XRD) and the pattern obtained is presented in Figure $1(b)$. In particular, diffractions derived from the $\alpha-\mathrm{FeOOH}, \beta$ $\mathrm{FeOOH}, \gamma-\mathrm{FeOOH}$, and $\mathrm{Fe}_{3} \mathrm{O}_{4}$ phases are observed, and clear peaks of $\gamma$ $\mathrm{FeOOH}$ are confirmed. In order to evaluate the rust layer quantitatively, the mass fractions of $\alpha-\mathrm{FeOOH}, \beta-\mathrm{FeOOH}, \gamma-\mathrm{FeOOH}$, and $\mathrm{Fe}_{3} \mathrm{O}_{4}$ (described as $M_{\alpha}, M_{\beta}, M_{\gamma}$, and $M_{\mathrm{s}}$, respectively) in the rust layer were calculated using the intensity of the diffraction peaks obtained for each crystalline phase $\left(I_{\square}, I_{\text {回, }}, I_{\text {回, }}\right.$, and $I_{\mathrm{S}}$, respectively), based on the following equation,

$M_{\mathrm{i}}=M_{\mathrm{iA}} \cdot\left(l_{\mathrm{V}} / l_{\mathrm{iA}}\right) / \Sigma\left(M_{\mathrm{jA}} \cdot l_{\mathrm{j}} / l_{\mathrm{jA}}\right)(\mathrm{i}, \mathrm{j}=\alpha, \beta, \gamma, \mathrm{S})$

where $l_{\mathrm{iA}}, l_{\mathrm{jA}}$ and $M_{\mathrm{iA}}, M_{\mathrm{jA}}$ are the reference diffraction intensities and the reference mass fractions, respectively, obtained from the reference rust used in our previous work. The details on the estimation are described in the literature. ${ }^{25)}$ The mass fractions computed for the as-rusted specimen were as follows: $21 \%$ for $\alpha-\mathrm{FeOOH}, 5 \%$ for $\beta$ $\mathrm{FeOOH}, 59 \%$ for $\gamma$ - $\mathrm{FeOOH}$ and $1 \%$ for $\mathrm{Fe}_{3} \mathrm{O}_{4}$.

After the cyclic corrosion test, the morphology and composition of the as-rusted specimen was observed to vary. Figure 2 shows the SEM images of the specimen surfaces. Notably, the specimens shown in Figures 2(b) - 2(e) were subjected to the additional immersion in the cation-containing solutions during the cyclic corrosion test whereas the reference specimens in Figure 2(a) were not subjected to the additional immersion. The morphology of the rust layers on the reference specimen is unchanged, as shown in Figure 2(a). However, drastic changes in morphology are observed for the specimens subjected to the additional immersion. Furthermore, the changes strongly depend on the solution used for the additional immersion. The morphological change from the plate-like to a flowery shape is confirmed for the $\mathrm{Mg}^{2+}$ specimens after the 3rd cycle. In addition, the flowery structure becomes finer with an increase in the number of cycles. For the other specimens subjected to the additional immersion, that is, for the $\mathrm{Al}^{3+}, \mathrm{Cu}^{2+}$ and $\mathrm{Ni}^{2+}$ specimens, a different morphological change to a cotton ball shape is recognized. The flowery and cotton ball structures were reported by Prakash et al. on a mild steel. ${ }^{21)}$ The rust layers with the finer flowery shape or the cotton ball shape are found to be more protective compared to those with a plate-like shape because the flowery or cotton ball shaped rust layers are more compact and dense due to fewer hollows, as displayed in Figure 2. In the following, the composition of the rust layers on these specimens is discussed. Figure 3 presents the mass fraction of the rust phase on the reference specimens and the specimens subjected to the additional immersion in the cation-containing solutions. In the figures, the result obtained for the as-rusted specimen is also included for comparison. For the reference specimens, the fraction of $\alpha-\mathrm{FeOOH}$ increases whereas the fraction of $\mathrm{\gamma}-\mathrm{FeOOH}$ clearly decreases. After 30 cycles, the fraction of $\alpha-\mathrm{FeOOH}$ reaches approximately $40 \%$.

Although a similar change is observed for the specimens subjected to the additional immersion, a further increase in $\alpha$-FeOOH is observed. For the $\mathrm{Mg}^{2+}$, and $\mathrm{Ni}^{2+}$ specimens, the fraction of $\alpha-\mathrm{FeOOH}$ after 30 cycles is around $50 \%$, which is slightly smaller compared to that of the $\mathrm{Al}^{3+}$, and $\mathrm{Cu}^{2+}$ specimens.

\subsection{Electrochemical property of rust layers}

Figure 4 (a) shows the representative polarization curve obtained from the as-rusted specimen. In the present work, the corrosion potential, 
$E_{\text {corr }}$ and the corrosion current density, $I_{\text {corr }}$, were evaluated by the extrapolation of Tafel slopes within the potential range of $\pm 100 \mathrm{mV}$ from $E_{\text {corr }} . E_{\text {corr }}$ and $I_{\text {corr }}$ for the as-rusted specimen are estimated as $414 \mathrm{mV}_{\mathrm{Ag} / \mathrm{AgCl}}$ and $0.028 \mathrm{~mA} \mathrm{~cm}^{-2}$, respectively. The same measurements were carried out for the other specimens, that is, the reference specimens and the specimens subjected to the additional immersion. The obtained $E_{\text {corr }}$ and $I_{\text {corr }}$ are summarized in Figures 4 (b) and $4(c)$. The results for the as-rusted specimen are also presented for comparison. As shown in Figure $4(\mathrm{~b})$, after the 3 rd cycle, the $E_{\text {corr }}$ for the reference specimens is almost similar to that for the as-rusted specimen, however, it increases slightly with cycling. For the $\mathrm{Al}^{3+}$ specimen, the $E_{\text {corr }}$ is less noble particularly in the18th and 30th cycle. For the other specimens, except for the reference specimens and the $\mathrm{Al}^{3+}$ specimens, the $E_{\text {corr }}$ tends to decrease once in the initial stage, and thereafter, increases with cycling. After the 30 cycle, the $E_{\text {corr }}$ of the $\mathrm{Al}^{3+}$ specimen is lower than that of the reference specimens whereas the $E_{\text {corr }}$ of the other specimens with the additional immersion is higher, particularly for the $\mathrm{Cu}^{2+}$ specimens. Figure 4 (c) reveals that the $I_{\text {corr }}$ of the reference specimens increases slightly with cycling compared to the $I_{\text {corr }}$ of $0.028 \mathrm{~mA} \mathrm{~cm}^{-2}$ for the as-rusted specimen. For the $\mathrm{Mg}^{2+}$ and $\mathrm{Ni}^{2+}$ specimens, the $I_{\text {corr }}$ increases once in the initial cycles and then decreases significantly in later cycles. However, the $I_{\text {corr }}$ for the $\mathrm{Al}^{3+}$ specimens decreases monotonically with cycling. From these variations, one can observe that in the later stages of the cyclic corrosion test, the $I_{\text {corr }}$ of these specimens is smaller than that of the as-rusted specimen. Contrastingly, the $I_{\text {corr }}$ for the $\mathrm{Cu}^{2+}$ specimens in the later stages is roughly comparable to that of the as-rusted specimen although the $I_{\text {corr }}$ fluctuates through the cycle. However, when compared to the reference specimens, all the specimens with the additional immersion exhibit a smaller $I_{\text {corr, }}$ indicating that the additional immersion in the cation-containing solutions increases the corrosion resistance of the as-rusted specimen in the later stages.

To evaluate the reduction reaction on the rust layers in addition to the $E_{\text {corr }}$ and $I_{\text {corr }}$, the cathodic polarization curves for all the specimens were measured, where the potential was swept with a rate of $0.5 \mathrm{mV} \mathrm{s}$ ${ }^{1}$ until it reaches $500 \mathrm{mV}$ lower than the open circuit potential of each specimen. Figure 5(a) shows the cathodic polarization curve obtained for the as-rusted specimen. It is clear that the cathodic polarization curve does not exhibit the current plateau related to the oxygen diffusion limit. In addition, interestingly, the cathodic current density is relatively larger than the oxygen diffusion-limited current density of approximately $25 \mu \mathrm{A} \mathrm{cm}-2$ on polished carbon steel. ${ }^{26,27)}$ This implies that the reduction of the rust layer occurs on the as-rusted layer, contributing to the cathodic current density. To examine the effects of the cations on the reduction of rust, a specific cathodic current density, $I_{c}$, was determined at $500 \mathrm{mV}$ less than the open circuit potential of each specimen from the cathodic polarization curve. For example, the $I_{c}$ for the as-rusted specimen was estimated as $0.92 \mathrm{~mA} \mathrm{~cm}^{-2}$ from the cathodic polarization curve shown in Figure 5(a). For the other specimens, the $I_{c}$ was determined by the cathodic polarization curves and is summarized in Figure $5(\mathrm{~b})$. The $I_{\mathrm{c}}$ for all specimens increases in the initial stage of the cyclic corrosion test, however, subsequent variations differ depending on the specimen. The $I_{c}$ of the reference specimen and the $\mathrm{Cu}^{2+}$ specimen decreases with cycling and then levels off to stable values, although the current densities for the 18th cycle are relatively larger than the stable values. On the other hand, the $I_{c}$ of the other specimens decreases monotonically with cycling after the initial increase, and finally converges to approximately $0.4 \mathrm{~mA} \mathrm{~cm}^{-2}$. It should be noted that each $I_{c}$ presented in Figure $5(\mathrm{~b})$ is larger than the oxygen diffusion-limited current density, indicating that the reduction of the rust layers occurs on all the specimens examined. Furthermore, the reduction is strongly affected by the cations.

\section{DISCUSSION}

\subsection{Effects of cations on the electrochemical properties of rusted steel}

In section 3.2, $E_{\text {corr }}$ and $I_{\text {corr }}$ are presented in Figures $4($ b) and 4(c), respectively. The relationship between $E_{\text {corr }}$ and $I_{\text {corr }}$ is summarized for all the specimens subjected to the cyclic corrosion test and is presented in Figure 6 . The data for the as-rusted specimen is also plotted as the star symbol, $\star$, in each figure. As apparent from Figure 6 , these correlations differ depending on the specimen. For the reference specimens, the $I_{\text {corr }}$ is almost comparable each other although a scatter in the data is observed. As described in section 3.1, the rust layers on the reference specimens are not adequately protective, thus, the rust layers cannot effectively suppress the penetration of the electrolytes to the steel substrate. For the $\mathrm{Mg}^{2+}$ and $\mathrm{Ni}^{2+}$ specimens, a relatively large $I_{\text {corr }}$ and a low $E_{\text {corr }}$ are confirmed in the initial stage. However, in the later stages, the $I_{\text {corr }}$ decreases and the $E_{\text {corr }}$ increases. These variations in the later stages imply that the anodic reaction is suppressed with cycling, which is probably due to the growth of the dense rust layers as indicated in Figure 2.

The dense rust layers grew on the other specimens such as the $\mathrm{Al}^{3+}$ and $\mathrm{Cu}^{2+}$ specimens, however, the correlation between $E_{\text {corr }}$ and $I_{\text {corr }}$ for the $\mathrm{Al}^{3+}$ and $\mathrm{Cu}^{2+}$ specimens is completely different from the correlation between $E_{\text {corr }}$ and $I_{\text {corr }}$ for the $\mathrm{Mg}^{2+}$ and $\mathrm{Ni}^{2+}$ specimens. For the $\mathrm{Al}^{3+}$ specimens, as shown in Figure 6(c), the $I_{\text {corr }}$ relatively decreases compared to the as-rusted specimen, but the $E_{\text {corr }}$ hardly increases, compared to the $\mathrm{Mg}^{2+}$ and $\mathrm{Ni}^{2+}$ specimens. Otani et al. investigated the corrosion behavior of a mild steel and an aluminum alloy, focusing on the effects of metallic cations in various salt solutions. ${ }^{28,29)}$ They described that compared to metallic cations with a small hardness, those with a high hardness ${ }^{29-31)}$, such as $\mathrm{Al}^{3+}$, are adsorbed into the thin oxide layer on the mild steel. ${ }^{28)}$ The hydroxide of the adsorbed metallic cation is formed for a short time. If a similar phenomenon is assumed to occur for $\mathrm{Al}^{3+}$, the adsorbed $\mathrm{Al}^{3+}$ could promote the formation of $\alpha$ $\mathrm{FeOOH}$, which is the dominant phase in the rust layers on the $\mathrm{Al}^{3+}$ specimen. As described above, $\alpha-\mathrm{FeOOH}$ is electrochemically stable, thus suppressing the cathodic reaction expressed in the equation (2). Therefore, these variations can be explained by a suppressed cathodic reaction. The $E_{\text {corr }}$ of the $\mathrm{Cu}^{2+}$ specimens drastically increases, compared to those of the other specimens. The higher $E_{\text {corr }}$ is considered to result from the acceleration of the cathodic reaction. The XRD analysis reveals that the mass fraction of $\mathrm{FeOOH}$ is larger for the $\mathrm{Cu}^{2+}$ specimens compared to those of the other specimens, as shown in Figure 3. The effect of $\mathrm{Cu}^{2+}$ on the oxidation reaction of $\mathrm{Fe}^{2+}$ was reported by Cher et al. and Stumm et al. ${ }^{32,33)}$ They found that $\mathrm{Cu}^{2+}$ catalyzed the oxidation of $\mathrm{Fe}^{2+}$ to $\mathrm{Fe}^{3+}$. Assuming the catalytic action of $\mathrm{Cu}^{2+}$, the increased amount of $\mathrm{FeOOH}$ is reasonably explained. The large amount of $\mathrm{FeOOH}$ can increase the reduction of rust described in the equation (2). Therefore, it can be concluded that $\mathrm{Cu}^{2+}$ increases the growth of $\mathrm{FeOOH}$, which results in the increase of the cathodic reaction. This could contribute to a higher $E_{\text {corr }}$ for the $\mathrm{Cu}^{2+}$ specimens. The above discussion implies that a large amount of $\mathrm{FeOOH}$ induces a higher $E_{\text {corr }}$. Figure 7 shows the relationship between $E_{\text {corr }}$ and the ratio of the total mass fraction of $\mathrm{FeOOH}$ to the mass fraction of $\mathrm{Fe}_{3} \mathrm{O}_{4}$. The total mass fraction is calculated from the sum of the mass fraction of $\alpha-\mathrm{FeOOH}, \beta-\mathrm{FeOOH}$ and $\gamma-\mathrm{FeOOH}$. A linear dependence between $E_{\text {corr }}$ and the ratio is obtained, indicating that $E_{\text {corr }}$ is strongly affected by the amount of $\mathrm{FeOOH}$. Contrastingly, $I_{\text {corr }}$ has been discussed in terms of the other index, $\alpha / \gamma^{*},{ }^{34-36)}$ where $\alpha$ and $\gamma^{*}$ indicate the mass fraction of $\alpha-\mathrm{FeOOH}$ and the total mass fractions of $\beta-\mathrm{FeOOH}, \nu-\mathrm{FeOOH}$, and $\mathrm{Fe}_{3} \mathrm{O}_{4}$, respectively. Figure 8 presents the relationship between $I_{\text {corr }}$ and $\alpha / \gamma^{*}$. In Figure $8, I_{\text {corr }}$ decreases with an increase in $\alpha / \gamma^{*}$. Kamimura et al. also found that the composition of the rust layer on weathering steel changes during atmospheric corrosion and the corrosion rate 
decreases with an increase in the index, $\left.\alpha / \gamma^{*} .34,36\right)$ This correlation between $I_{\text {corr }}$ and the index suggests that $I_{\text {corr }}$ is reduced due to the growth of a certain amount of $\alpha-\mathrm{FeOOH}$.

\subsection{Influence of the reduction of rusts on corrosion current density}

Evans developed an electrochemical model on the atmospheric corrosion of iron in wet-dry cyclic conditions. In the model, during the wet period, the anodic dissolution of iron under a porous rust layer was balanced by the cathodic reduction of $\mathrm{FeOOH}$, which is expressed in the equation (2). The re-oxidation of $\mathrm{Fe}_{3} \mathrm{O}_{4}$ subsequently occurs in the drying period, according to the equation (3). The reduction of $\mathrm{FeOOH}$ and the re-oxidation of $\mathrm{Fe}_{3} \mathrm{O}_{4}$ repeatedly occur in wet-dry cycles. It was reported that $\gamma-\mathrm{FeOOH}$ can be easily reduced to $\mathrm{Fe}_{3} \mathrm{O}_{4}$ whereas $\alpha-\mathrm{FeOOH}$ is stable and can scarcely be reduced. ${ }^{37-39)}$ Therefore, $\alpha-\mathrm{FeOOH}$ is found to suppress the reduction of rust, which is in accordance with the finding obtained from Figures 3 and $5(b)$. The reference specimens with a relatively low fraction of $\alpha-\mathrm{FeOOH}$ in the rust layer exhibit a higher $I_{c}$. However, the other specimens with a higher $\alpha$-FeOOH fraction exhibit a lower $I_{c}$ compared to the reference specimens. From the above-mentioned discussion, one can deduce that a lower $I_{c}$ is related to the suppressed reduction of rust. Figure 9 shows the relationship between $I_{c}$ and $I_{\text {corr }}$, also shown in Figures 4 (c) and $5(b)$, respectively. $I_{\text {corr }}$ decreases with a decrease in $I_{c}$. This demonstrates that the corrosion current density, $I_{\text {corr }}$, on rusted steel is strongly related to the reduction current density of the rust, $I_{c}$, indicating that the corrosion rate of carbon steel in an atmospheric environment is significantly dominated by the reductive property of a rust layer on the steel. The present work clearly demonstrates that the reductive property of a rust layer on carbon steel can be modified with an immersion in a cation-containing solution, that is, the introduction of a cation into the rust layer. This modification results in an improved corrosion resistance of carbon steel experiencing atmospheric corrosion. However, further works are required to confirm the feasibility of the present results to rusts grown after longer exposures to the environment. In addition, the synergistic effects of the cations on the modification of a rust layer on carbon steel can be expected, that is, the growth of $\alpha-\mathrm{FeOOH}$ can be facilitated by the immersion of a rust layer in mixed solutions of the cations. These will be examined in the near future.

\section{CONCLUSIONS}

In the present work, a cyclic corrosion test for a model rust layer grown on carbon steel was performed to examine the modification of the morphology, composition and electrochemical properties of the rust layer by the introduction of metallic cations such as $\mathrm{Mg}^{2+}, \mathrm{Al}^{3+}, \mathrm{Cu}^{2+}$, or $\mathrm{Ni}^{2+}$. The introduction of metallic cation was realized by the additional immersion of the rust layer in the cation-containing solutions during the cyclic corrosion test. Based on the morphological and compositional characterization as well as the electrochemical measurements obtained for the rust layers after the cyclic corrosion test, the following conclusions are drawn.

* The fraction of $\alpha-\mathrm{FeOOH}$ in the rust layers after the cyclic corrosion test was higher for the specimens subjected to the additional immersion, compared to that for the reference specimens not subjected to the additional immersion.

* The additional immersion affected the corrosion potential, $E_{\text {corr, }}$ of the rusted steel as well as the corrosion current density, $I_{\text {corr. }}$.
* The $E_{\text {corr }}-I_{\text {corr }}$ plot indicated that the rust layers on the $\mathrm{Mg}^{2+}$ and the $\mathrm{Ni}^{2+}$ specimens suppressed an anodic reaction whereas the rust layers on the $\mathrm{Al}^{3+}$ specimen retarded a cathodic reaction.

* The correlation between $I_{\text {corr }}$ and the cathodic current density, $I_{c}$, of the rust layers revealed that the atmospheric corrosion of carbon steel may be dominated by cathodic reaction.

* A clear correlation between $I_{\text {corr }}$ and the mass fraction of $\alpha-\mathrm{FeOOH}$ in the rust layer was recognized, implying that the modification of rust layers by the introduction of metallic cations will be effective in suppressing the atmospheric corrosion of carbon steel.

\section{ACKNOWLEDGEMENTS}

The present work was supported by a Grant-in-Aid for Scientific Research (B) (Project No. 19H02479) from the Japan Society for the Promotion of Science.

\section{References}

1. R.D.K. Misra, G.C. Weatherly, J.E. Hartmann, A.J. Boucek, Mater. Sci. Technol. 17 (2001): p. 1119-1129.

2. C. L. Davis, J. E. King, Mater. Sci. Technol. 9 (1993): p. 8-15

3. C. Miki, K. Homma, T. Tominaga, J. Constr. Steel Res. 58 (2002): p. 3-20.

4. T. Kitada, J. Constr. Steel Res. 62 (2006): p. 1192-1198.

5. U.R. Evans, C.A.J. Taylor, Corros. Sci. 12 (1972): p. 227-246.

6. M.V. Biezma, F. Schanack, J. Perform. Constr. Facil. 21 (2007): p. 398-405.

7. E. Mirambell, Prog. Struct. Engng Mater 6 (2004): p. 56-68.

8. R. Cornell, U. Schwertmann, The Iron Oxides, Structure, Properties, Reactions, Occurrences and Uses, Second Completely Revised and Extended Edition (2003).

9. M. Morcillo, J.M. González-Calbet, J.A. Jiménez, I. Díaz, J. Alcántara, B. Chico, A. Mazarío-Fernández, Corrosion 71 (2015): p. 872-886.

10. J. Calero, J. Alcántara, B. Chico, I. Díaz, J. Simancas, D. de la Fuente, M. Morcillo, Corros. Eng. Sci. Tech. 52 (2017): p.178-187.

11. H. Tanaka, A. Miyafuji, K. Kandori, T. Ishikawa, T. Nakayama, Corros. Sci. 66 (2013): p. 337-342.

12. J. Monnier, P. Dillmann, L. Legrand, I. Guillot, Corros. Eng., Sci. Technol. 45 (2010): p. 375-380.

13. M. Yamashita, H. Miyuki, T. Matsuda, H. Nagano, T. Misawa, Corros. Sci. 36 (1994): p. 283-299.

14. M. Yamashita, K. Asami, T. Ishikawa, T. Ohtsuka, H. Tamura, T. Misawa, Zairyo-to-Kankyo 50 (2001): p. 521-530.

15. H. Okada, Y. Hosoi, K. Yukawa, H. Naito, Tetsu-to-Hagane 55 (1969): p. 355-365.

16. Z. Wang, J. Liu, L. Wu, R. Han, Y. Sun, Corros. Sci. 67 (2013): p. 110.

17. H. Cano, I. Díaz, D. de la Fuente, B. Chico, M. Morcillo, Mater. Corros. 69 (2018): p. 8-19.

18. SAE J2334, Cosmetic Corrosion Lab Test, 1998. SAE International, Warrendale, PA.

19. T. Kamimura, K. Kashima, K. Sugae, H. Miyuki, T. Kudo, Corros. Sci. 62 (2012): p. 34-41.

20. D.P. Schmidt, B.A. Shaw, E. Sikora, W.W. Shaw, L.H. Laliberte, Corrosion 63 (2007): p.958-974.

21. M. Prakash, S. Shekhar, A.P. Moon, K. Mondal, J. Mater. Process. Technol. 219 (2015): p.70-83.

22. J.G. Castaño, C.A. Botero, A.H. Restrepo, E.A. Agudelo, E. Correa, F. Echeverría, Corros. Sci. 52 (2010): p. 216-223.

23. D. de la Fuente, I. Díaz, J. Simancas, B. Chico, M. Morcillo, Corros. Sci. 53 (2011): p. 604-617. 
24. R.A. Antunes, I. Costa, D.L.A. de Faria, Mater. Res. 6 (2003): p. 403-408.

25. S. Hara, M. Yamashita, T. Kamimura, M. Sato, J. Japan Inst. Met. 71 (2007): p. 346-353.

26. J. R. Park, K. Y. Kim, Corrosion 64 (2008): p. 4-14.

27. E. McCafferty, Corros. Sci. 47 (2005): p. 3202-3215.

28. K. Otani, M. Sakairi, Corros. Sci. 111 (2016) : p. 302-312.

29. K. Otani, M. Sakairi, R. Sasaki, A. Kaneko, Y. Seki, J. Solid State Electrochem. 18 (2014): p. 325-332.

30. R.G. Pearson, J. Am. Chem. Soc. 85 (1963): p. 3533-3539.

31. M. Misono, E. Ochiai, Y. Saito, Y. Yoneda, J. Inorg. Nucl. Chem. 29 (1967): p. 2685-2691.

32. M. Cher, N. Davidson, J. Am. Chem. Soc. 77 (1955): p.793-798.

33. W. Stumm, G. F. Lee, Ind. Eng. Chem. 53 (1961): p. 143-146.

34. T. Kamimura, S. Hara, H. Miyuki, M. Yamashita, H. Uchida, Corros. Sci. 48 (2006): p.2799-2812.

35. T. Kamimura, M. Yamashita, H. Uchida, H. Miyuki, J. Jpn. Inst. Met. 65 (2001): p .922-928.

36. S. Hara, T. Kamimura, H. Miyuki, M. Yamashita, Corros. Sci. 49 (2007): p. 1131-1142.

37. J.T. Keiser, C.W. Brown, R.H. Heidersbach, J. Electrochem. Soc. 129 (1982): p. 2686-2689.

38. I. Suzuki, N. Masuko, Y. Hisamatsu, Corros. Sci. 19 (1979): p. 521535.

39. H. Okada, Y. Hosoi, H. Naito, Corrosion 26 (1970): p. 429-430.

\section{FIGURE CAPTIONS}

FIGURE 1. (a) SEM image, (b) XRD pattern, (c, d) polarization curves obtained for the as-rusted specimen.

FIGURE 2. SEM images of the specimen surfaces subjected to the cyclic corrosion test of 3, 9, 18 and 30 cycles; (a) reference, (b) $\mathrm{Mg}^{2+}$, (c) $\mathrm{Al}^{3+}$, (d) $\mathrm{Cu}^{2+}$, (e) $\mathrm{Ni}^{2+}$ specimens.

FIGURE 3. XRD quantitative analysis obtained from the specimens after the cyclic corrosion test: (a) reference, (b) $\mathrm{Mg}^{2+}$, (c) $\mathrm{Al}^{3+}$, (d) $\mathrm{Cu}^{2+}$, (e) $\mathrm{Ni}^{2+}$ specimens.

FIGURE 4. (a) Corrosion potential, $E_{\text {corr }}$ and (b) corrosion current density, $I_{\text {corr }}$, obtained from all specimens subjected to the cyclic corrosion test. Those obtained for the as-rusted specimen are included for comparison.

FIGURE 5. Specific cathodic current density obtained at $500 \mathrm{mV}$ less than the open circuit potential of all specimens subjected to the cyclic corrosion test. The cathodic currnet density of $0.92 \mathrm{~mA} \mathrm{~cm}^{-2}$ obtained for the as-rusted specimen is included as a reference.

FIGURE 6. Relationship between $E_{\text {corr }}$ and $I_{\text {corr }}$ obtained after defined cycles of the cyclic corrosion test. The data for the as-rusted specimen is presented as a reference.

FIGURE 7. Relationship between corrosion potential, $E_{\text {corr }}$ and the ratio of total mass fraction of $\alpha-\mathrm{FeOOH}, \beta-\mathrm{FeOOH}$ and $\gamma-\mathrm{FeOOH}$ to that of $\mathrm{Fe}_{3} \mathrm{O}_{4}$ obtained from the specimens after 30 cycles of the cyclic corrosion test.

FIGURE 8. Relationship between corrosion current density, $I_{\text {corr, }}$ and $\alpha / \gamma^{*}$.

FIGURE 9. Relationship between corrosion current density, $I_{\text {corr, }}$ and cathodic current density, $I_{\text {corr }}$. 
FIGURE 1
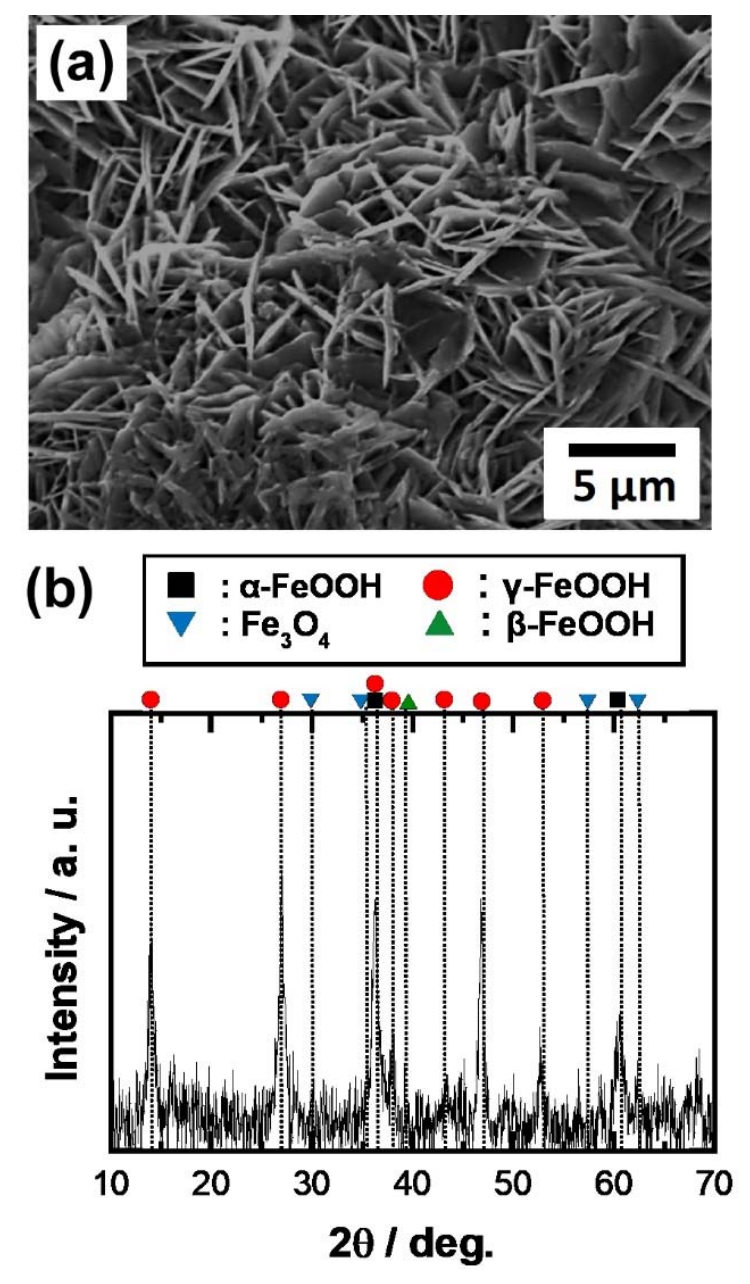


\section{FIGURE 2}
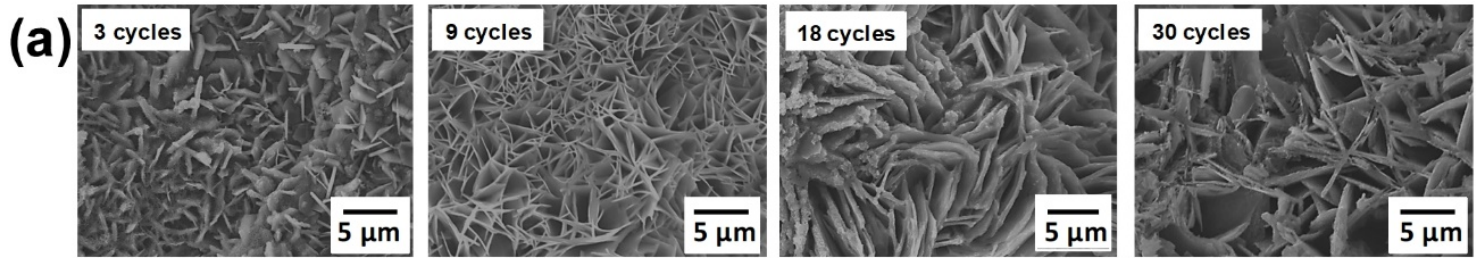

(b)
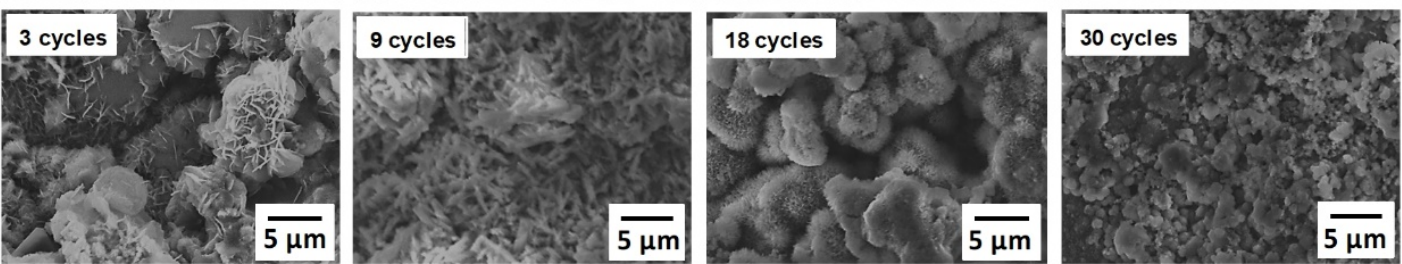

(c)
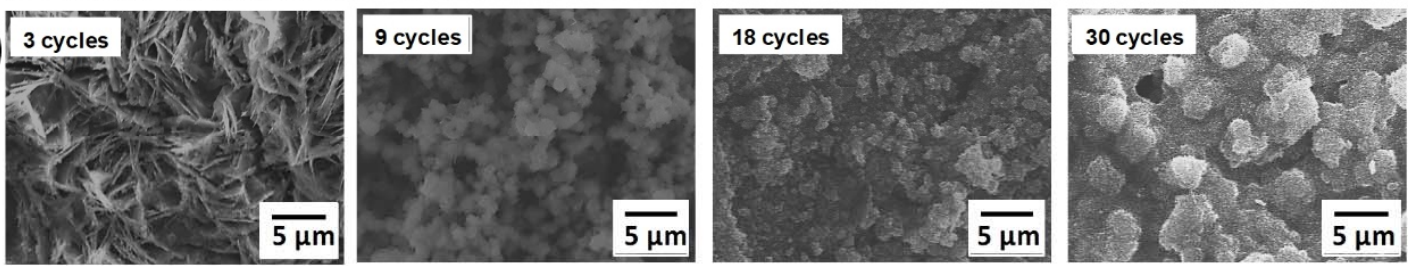

(d)
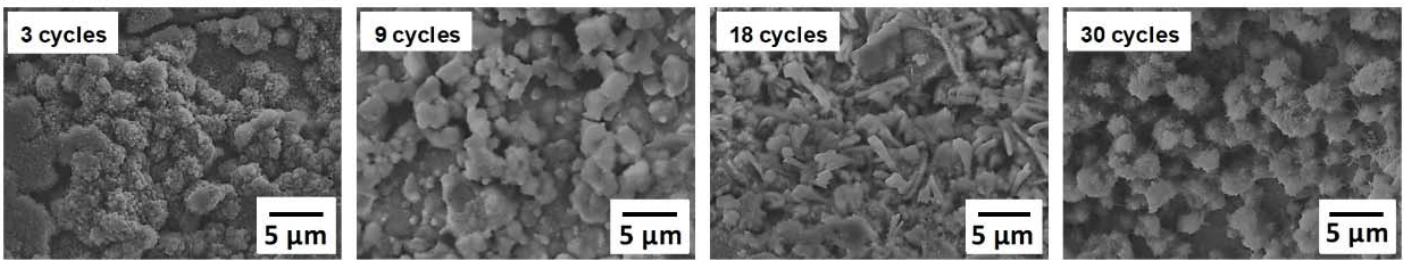

(e)
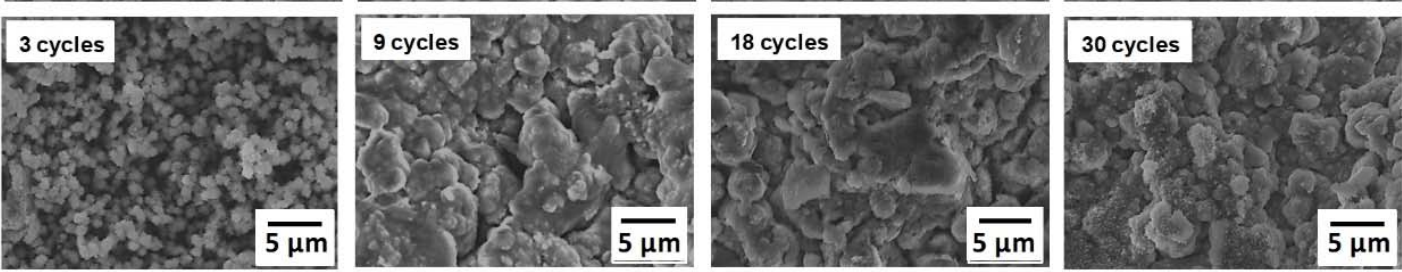
FIGURE 3

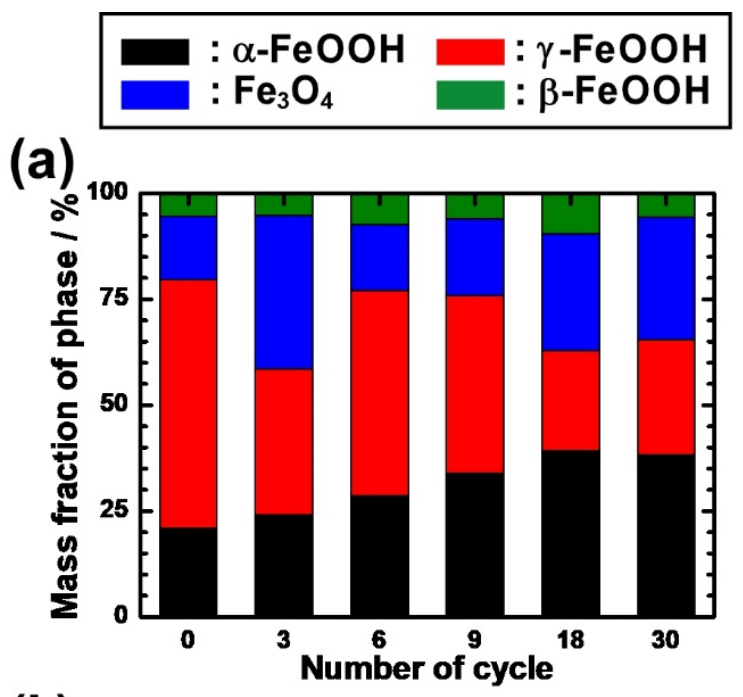

(b)

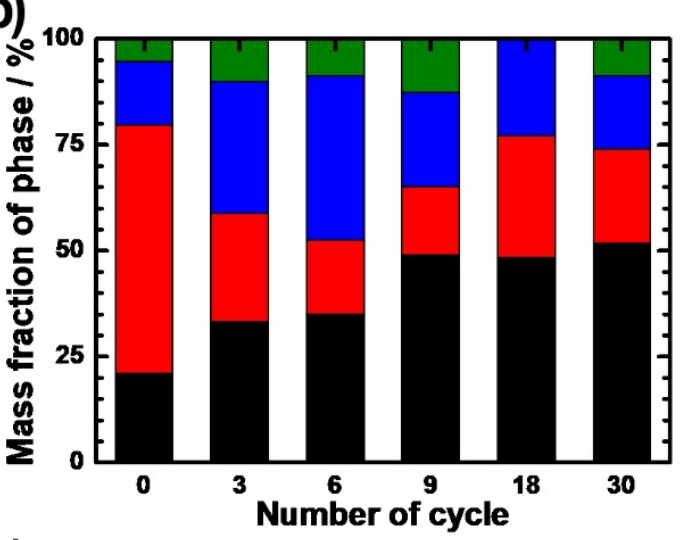

(c)

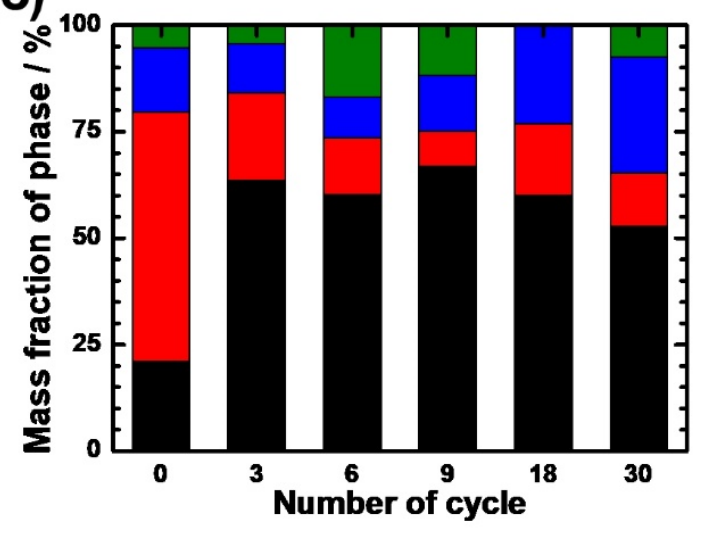


FIGURE 3 (continued)

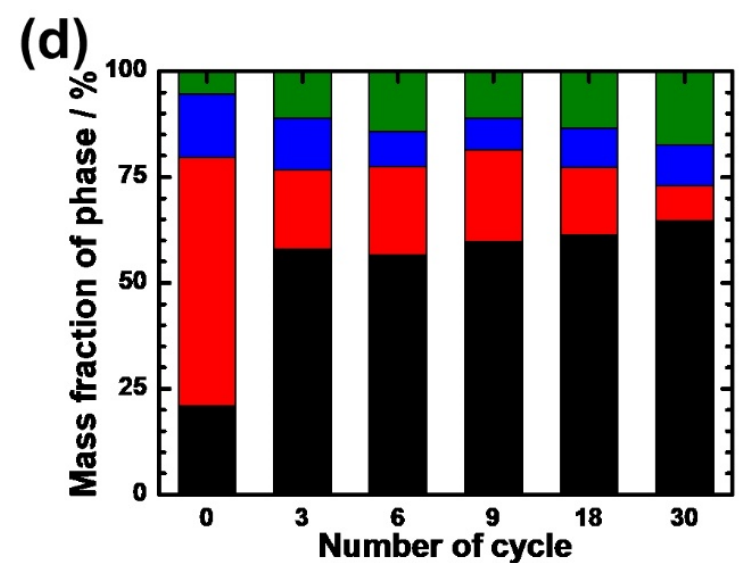

(e)

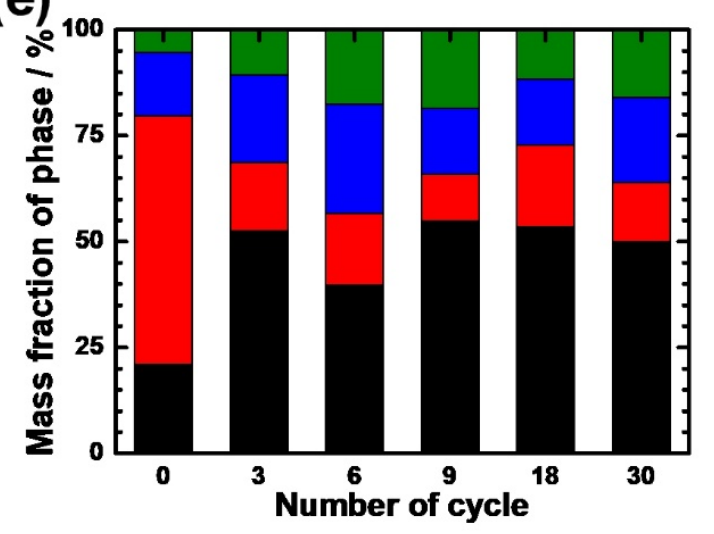


FIGURE 4
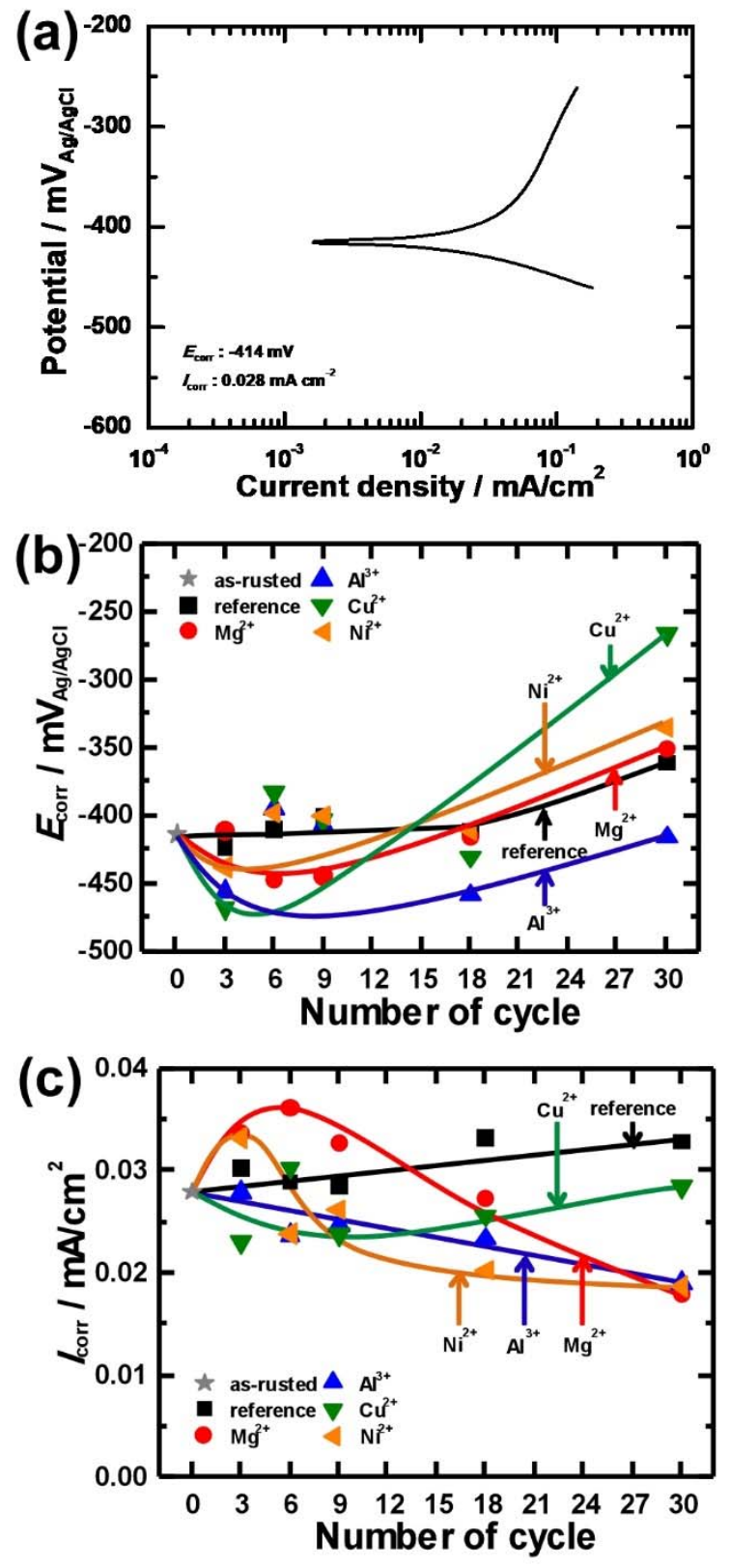


\section{FIGURE 5}
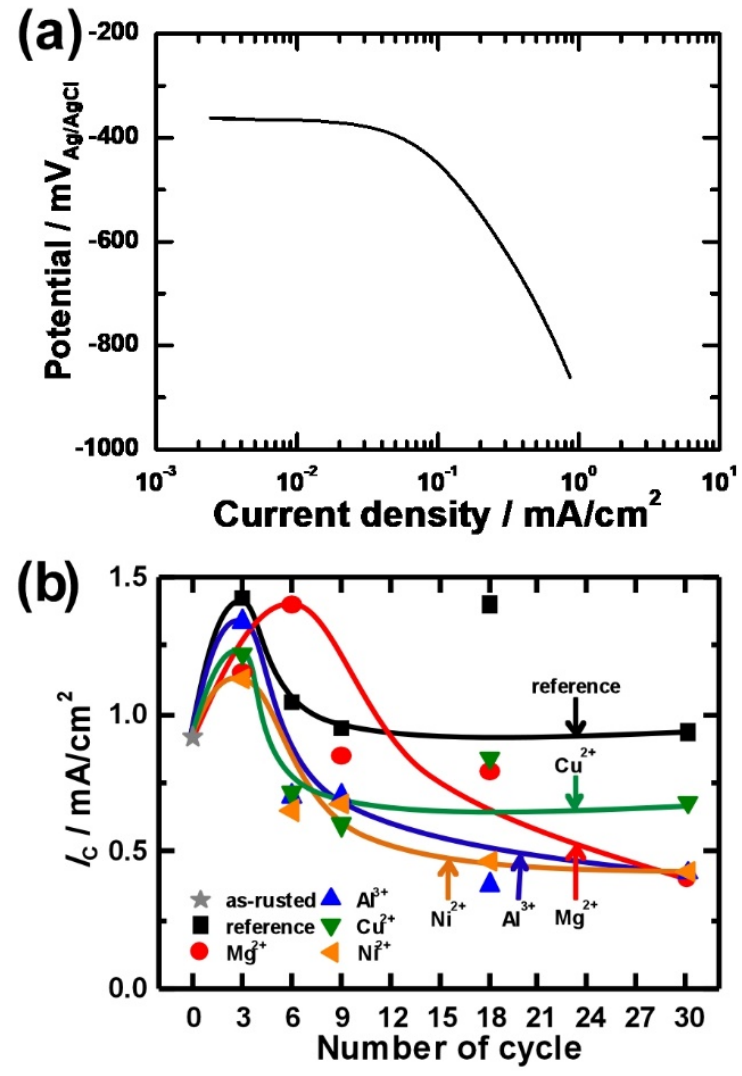
FIGURE 6
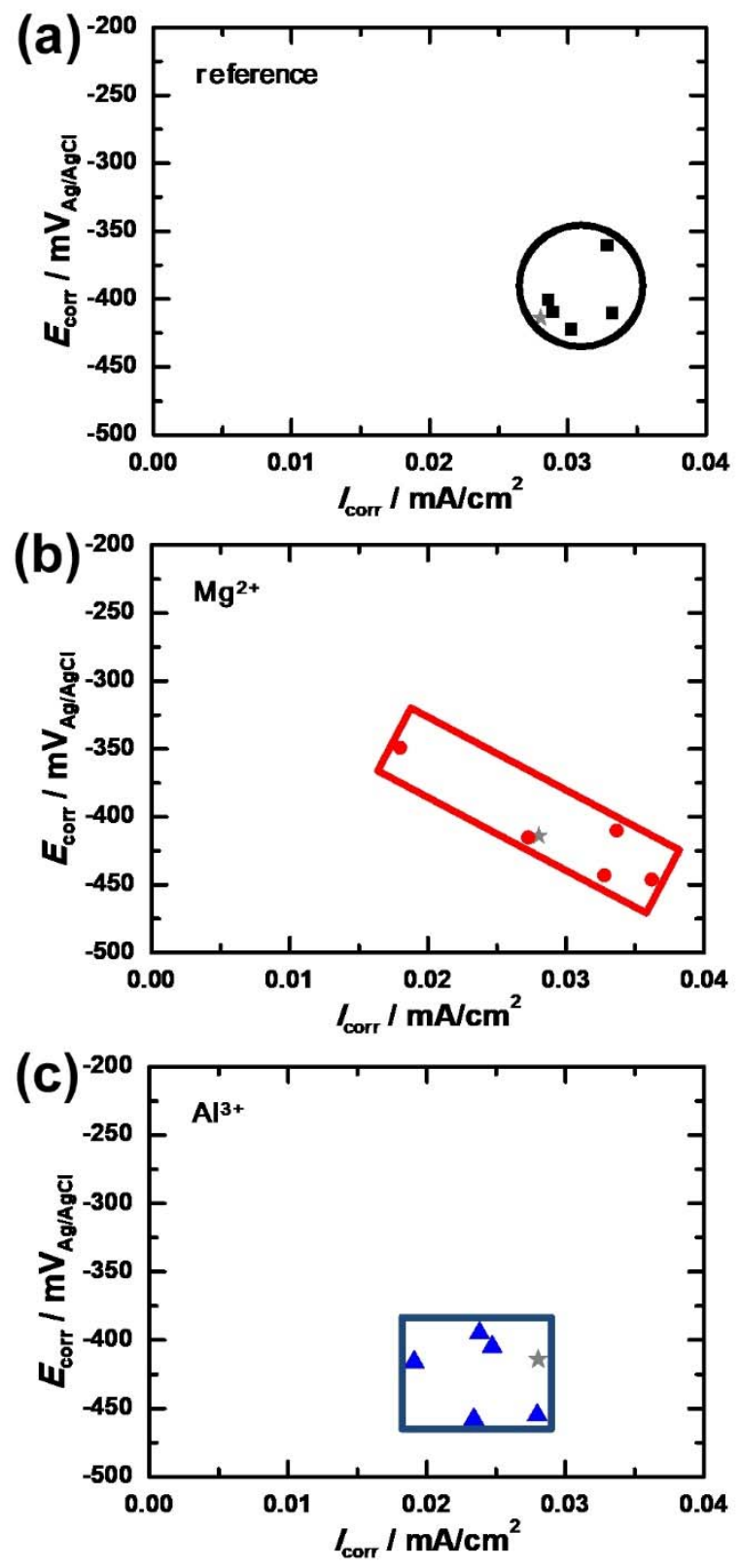
FIGURE 6 (continued)
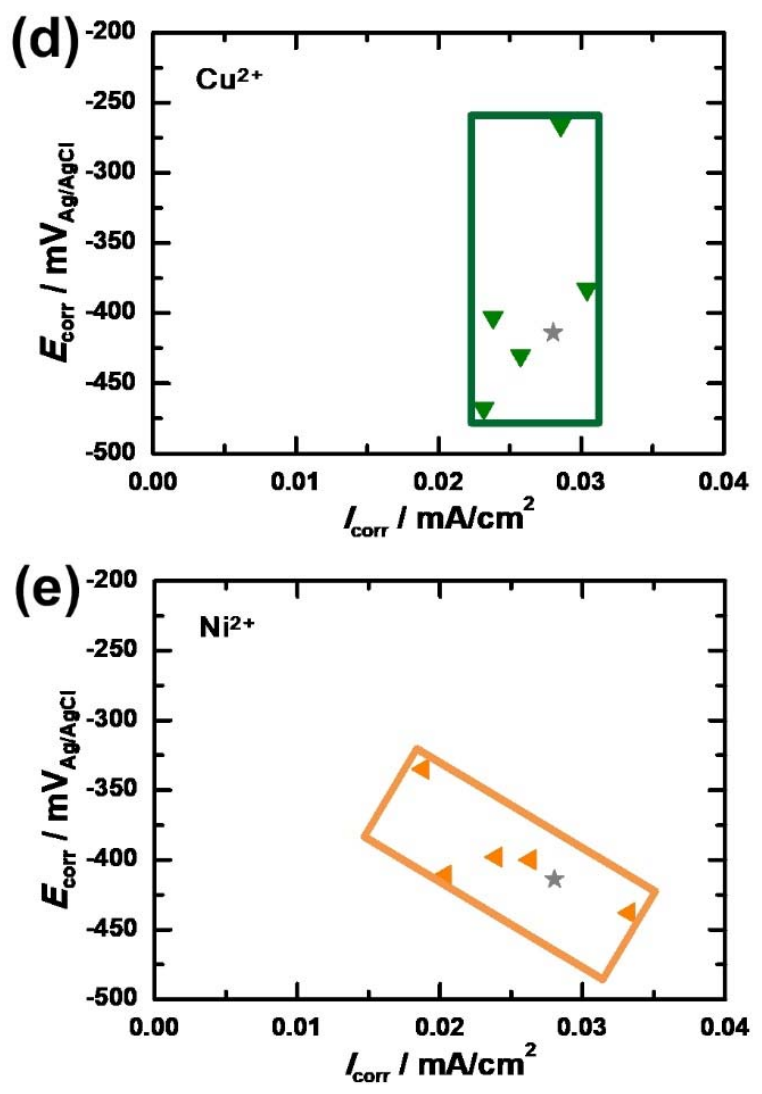
FIGURE 7

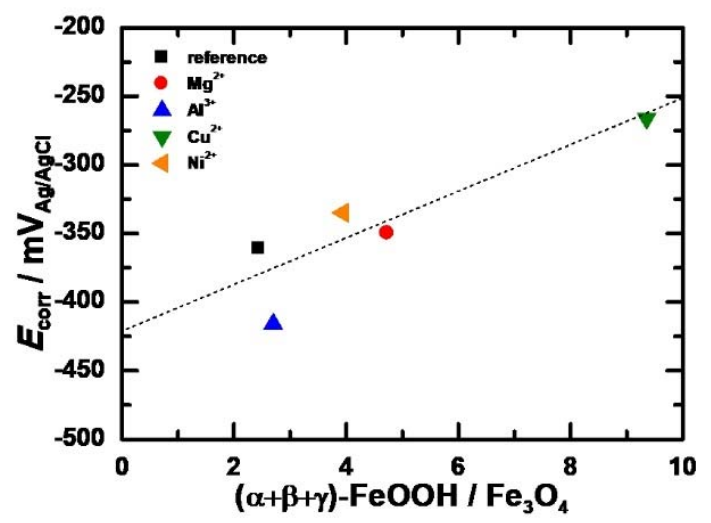




\section{FIGURE 8}

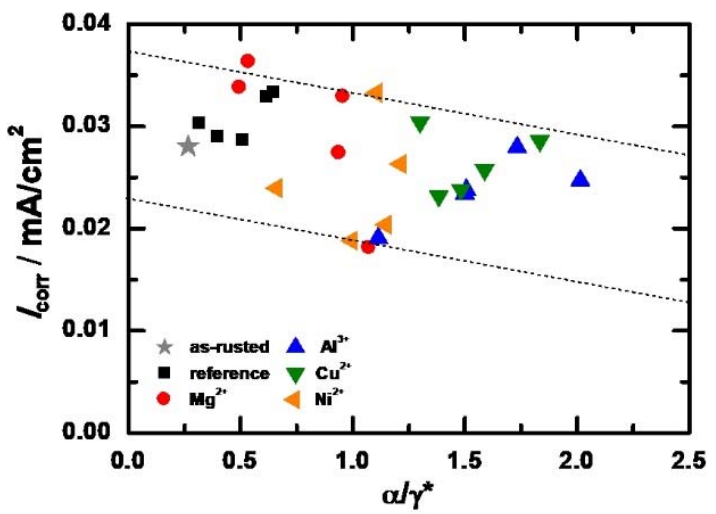


FIGURE 9

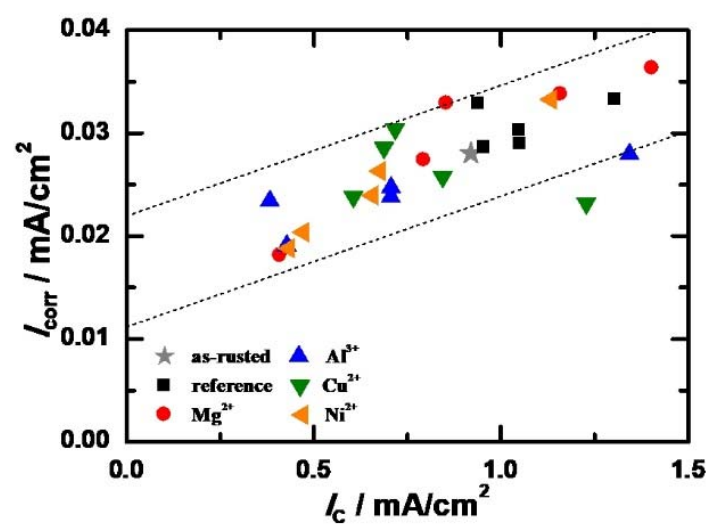

